\title{
Research on the Influence of Inclusive Leadership on Employees' Innovative Behavior
}

\author{
Chao Zhang ${ }^{\mathrm{a}}$, Lu Ma ${ }^{\mathrm{b}}$ \\ School of Management, Guangxi University of Technology and Science, Liuzhou 545006, China \\ a908192601@qq.com, bmalu6655@163.com
}

Keywords: Inclusive leadership; employee innovation behavior; work autonomy.

\begin{abstract}
Complex and quick change of the social environment so that today's enterprises are faced with unprecedented survival and development pressures, continuous innovation is the only way to win the enterprise. In order to accelerate innovation, ease the pressure of survival, many companies began to focus on employee innovation. After entering the 21st century, the economy is becoming more and more globalized, the political trend is diversified and the business environment is becoming more and more complicated. The employees of the new economic era such as the new generation staff and the knowledge workers are required to meet their differentiated needs and work autonomy requirements. Under the new economic background and management context, inclusive leadership has become a new type of leadership that is of concern. On the basis of analyzing the development process and concept of the inclusive leadership, this paper summarizes the structure and measurement methods of the inclusive leadership, and combs, prospects and summarizes the future research direction of the inclusive leadership style.
\end{abstract}

\section{Introduction}

The twenty-first century is the most important talent, and talent is the most important innovation. As an important organizational situation, leadership style has an important influence on the innovation behavior of employees. There are studies that confirm that the authoritative leadership style has a negative impact on the innovation behavior of employees. Transformational leadership is positively related to the innovative behavior of knowledge workers.

Employee innovation behavior is very different from the general behavior that is done only to complete the task, and it is influenced by various factors in the organization. And most scholars believe that the leader as the soul of organization and management, its leadership behavior can have an important impact on the staff's innovation, especially in recent years, the organization of external environment and internal conditions of change, requiring leadership to evolve with the times perfect. In contrast to the leadership of previous research, inclusive leadership is a special form and core of relational leadership, which explores the mechanism of leadership from the relationship between leaders and followers and advocates that leaders insist People-oriented management principles focus on whether leaders can listen and follow the needs of followers and demonstrate openness, effectiveness, and accessibility in interactions with followers (Carmeli et al., 2010). Inclusive leadership as an emerging field of leadership research, reflects the needs of researchers and practitioners in the context of specific times in the context of the new leadership style, is a better way to integrate people and things, to adapt to the management of the leadership of the complex.

\section{Research on the Related variables of Inclusive Leadership}

\subsection{The Presentation and Development of the Concept of Inclusive Leadership}

The concept of inclusive leadership style was first proposed in the field of education. For students with diversified, different races, different levels, different gender and different abilities, schools need inclusive leadership style [1]. University to adapt to economic, social, political and cultural development, to meet the needs of the community, colleges and universities need inclusive style, emphasizing dialogue and social righteousness. Ryan (2007) argues that the school's inclusive 
leadership style emphasizes the involvement of stakeholders in governance and management and is an equal collective leadership process ${ }^{[2]}$. In the field of management, Nembhard and Edmondson in 2006 cited the concept of inclusive leadership style ${ }^{[3]}$. They believe that inclusive leadership accepts and appreciates employees, accepts employee opinions and contributions, encourages and appreciates the efforts of employees. In this relationship in the important role of attention to followers of the leadership of the perception ${ }^{[4]}$. He believes that the cooperation between leaders and their followers is the essence of inclusiveness, and the key elements that contribute to the two-way success of this relationship are: respect, recognition, response and responsibility. Carmeli, Reiter-Palmon, and Ziv (2010) argue that inclusive leadership is a concrete, relational style of leadership that refers to openness, accessibility, and help in communicating with employees. A leader of the ${ }^{[5]}$. Ospina (2011) describes inclusive leadership as a valuable leader in accepting all levels of the organization, responsible for the end result, and an inclusive leader is the foundation and key to forming an inclusive organization ${ }^{[6]}$.

\subsection{Research on the concept of employee innovation behavior}

Innovation is an important source of organizational gaining competitive advantage. Since the 1980 s, the turbulent market environment requires companies to innovate in order to remain invincible in the competition. Innovation can be divided into individual, group and organizational levels, but the individual is the ultimate source of innovation (Woodman, 1993) ${ }^{[7]}$. Has a group of active and innovative, innovative staff to become the survival and development of contemporary enterprises one of the important conditions. Amabile (1988) also argues that employee creativity is the most important factor in organizational innovation and is the foundation of organizational innovation ${ }^{[8]}$. Therefore, how to stimulate the innovation of employees has become a hot topic in the field of organizational behavior. Employee innovation is a concept related to employee creativity. In the organization, the definition of employee creativity is different from other ideas and things, can bring long-term role for the organization or short-term behavior, are regarded as the creativity of the staff. In other words, employee creativity refers to the creation of novel and potentially valuable things or ideas, including new products, services, manufacturing methods and management processes, which can encourage enterprises to survive, innovate and grow in the fierce competition (Amabile, 1988) ${ }^{[8]}$. In addition to creating creative ideas, employee innovation involves the successful implementation of creative ideas. Scott \& Bruce (1994) argues that individual innovation begins with identifying problems, creating innovative ideas or solutions, finding support for their own ideas, and "productizing" and "institutionalizing" innovative ideas. The ideas that arise in innovation can be novel, others have never been used, and others have been used in other environments ${ }^{[9]}$. Zhou \& George (2001) also argues that individual innovation does not just refer to innovative ideas, but rather to the implementation of innovative ideas, content, promotion and development ${ }^{[10]}$.

\subsection{The concept of emotional trust and research}

In the early trust research, most scholars regarded trust simply as a one-dimensional variable and developed a corresponding trust measurement scale for empirical research. Among them, the more influential scale is Cook and Wall (1980) developed in the work of the interpersonal trust scale. The scale includes 12 measurement terms, but its internal consistency coefficient is low, only 0.60 , the lower consistency coefficient indicates that trust is more likely to be multidimensional variables , and that the organization developed by Ashford et al. (1989) Although the internal consistency coefficient of the trust scale reaches 0.78 , it includes only two terms of measurement.

Some scholars have divided the dimensions of trust from the perspective of trustees. For example, McAllister (1995) divides trust into cognitive trust and emotional trust ; Lewicki and Bunker (1995; citation from Zheng Bogui, 1999) divide trust into computational trust, knowledge-based trust and identity trust. McAllister (1995) is based on a cognitive measure developed by cognitive and emotional dimensions, consisting of 11 measurement terms, where the cognitive dimension consists of six measurement terms, an internal consistency coefficient of 0.91 , and an emotional dimension of five measurement terms, The internal consistency coefficient was 0.89 , but he did not test the validity of the scale. Although the scale is based on the research and development of managers, but for the 
trust of ordinary employees also apply, many scholars have used the scale of the trust of employees to measure , the scale has become the most famous Trust measurement scale.

\subsection{Distribution Fairness and Research}

On the distribution of fair connotation, the views of scholars are not consistent. Ding Bogen (1991) sums up the definition of distributive justice in three ways: the distribution of fairness is that the income earned by the individual is equal to his contribution to the gross national product, due to the compensation for the difference between the individual's endowment and its effort Income inequality, fair income distribution must equal to the welfare of each person. Rawls argues that equitable distribution focuses on "equality of results" and that the distribution of socio-economic and wealth should "benefit the best interests of the most disadvantaged members of society" .

\section{Inclusive leadership and employee innovation behavior research}

\subsection{Research on the Relationship between Inclusive Leadership and Employee Innovation Behavior}

Hollander (2009) argues that the principle of reciprocity in social exchange theory suggests that when employees get economic and social emotional resources in their organizations, they will have a sense of responsibility for return organizations. Leadership and subordinates are based on respect, recognition, responsiveness and responsibility to work together and pursue a win-win situation, thus enabling employees to reward organizations with "high performance or creative work". Second, the "openness" and "effectiveness" of the inclusive leadership require the leader to be adventurous and to support innovative behavior .

According to the theory of social learning, the adventurous spirit of leadership and its own innovative behavior can play a demonstration effect, providing employees with an example of learning, so as to promote employees to innovate . Again, the "accessible" of the inclusive leadership gives the subordinates' perceived proximity to the establishment of high-quality leadership relations . In the context of high-quality leadership relationships, employees do not have to worry about failure and show more creative behavior. In the face of practical problems, inclusive leadership generally pay attention to listen to the views of subordinates, which will allow employees to feel the safety of behavior, can effectively stimulate the creative thinking of the burst .

\subsection{Research on the Relationship between Emotional Trust and Employee Innovation Behavior and Inclusive Leadership}

Although the dimensions of trust have many different results, these dimensions can eventually be classified as both cognitive and emotional. Trust as a state of mind, is the cognitive rational thinking and emotional perceptual pay the combination of the two products, so the two basic dimensions of trust to include a rational cognitive and irrational emotions. Accordingly, interpersonal trust in the organization can be divided into cognitive and emotional trust. Among them, cognitive trust is based on beliefs about the credibility and reliability of others. This is based on the experience of rational judgments of the results, according to certain reasons to believe that the other's ability, integrity, honesty, justice and reliability and other personal characteristics. Emotional trust is based on mutual care and care, reflecting the specific emotional connection between the two sides of the trust. Trusters believe that the object of trust really concerned about their own interests, resulting in emotional attachment and investment.

\subsection{Research on the Relationship between Equity and Inclusive Leadership and Emotional Trust}

The distribution of a fair relationship model is based on the theory of social identity and fairness. Social identity theory holds that distributive equity affects employees 'perception of leadership legitimacy by influencing employees' trust and social identity. In the view of employees, fair distribution can act as a measure of leadership credibility and correctness, and a sense of fairness can influence employees' trust in leadership; and if employees perceive that organizational decisions are fair, it is easier Of the units and their representatives to produce social identity. This higher level of trust and social identity makes it easier for employees to recognize and accept the influence of leadership . 


\section{Summary}

This chapter systematically summarizes the concept connotation, measurement dimension, influencing factors and the related research among the variables such as inclusive leadership, employee innovation behavior, emotional trust and distribution fairness. On the one hand is to better grasp the research theme, to understand the relevant variables of research progress, on the other hand is to find a breakthrough from the existing research results, and then through the improvement and expansion of existing research to make new contributions. After summarizing we found:

(1) At present, the academic research has made great achievements in the research of employee innovation behavior, but the research on inclusive leadership is still in the stage of development. At the same time, the mechanism of incentive leadership is still in the exploratory stage. Exploring the Influencing Factors of Employee Innovation Behavior.

(2) Most studies show that emotional trust as a positive individual psychological factors, the individual behavior has an important guiding role, and then the inclusive leadership on the impact of innovative employee's behavior, emotional trust play a mediating role, and this whether the mediating role is regulated by the distribution of employees perceived by equity, which requires further research.

\section{Acknowledgements}

Innovation Project of Guangxi University of Science and Technology Graduate Education, NO:GKYC201612.

\section{References}

[1] Garrison-Wade,D.,Sobel,O., Fulmer, C. L. Inclusive leadership :Preparing principals for the role that awaits them. Educational Leadership and Administration,2006, 19:117-126

[2] Ryan,J.Inclusive leadership: A review. Journal of Education Administration and Foundation, 2007, 18:92-125

[3] Nembhard,I.M.,Edmondson,A.C..Making it safe: The effects of leader inclusiveness and professional status on psychological safety and improvement efforts in health care teams.Journal of Organizational Behavior,2006,27: 941-966

[4] Hollander E.P.Inclusive leadership :The essential leader -follower relationship.Taylor \& Francis Group,2009:3-6

[5] Carmeli,A.,Reiter-Palmon,R.,Ziv,E. Inclusive leadership and employee involvement in creative tasks in the workplace: The mediating role of Psychological Safety.Creativity Re-search Journal, 2010,22(3):250 -260

[6] Ospina,S.Leadership,Diversity and Inclusion: Insights from Scholarship. Graduate School of Public Service,2011,3:3-30

[7] Woodman R W, Sawyer J E, Griffin R W. Toward a theory of organizational creativity [J]. Academy of Management Review. 1993, 18(2): 293-321

[8] Amabile T M. A model of creativity and innovation in organizations[J]. Research in Organizational Behavior. 1988, 10(1): 123-167

[9] Scott S G, Bruce R A. Determinants of Innovative Behavior: A Path Model of Individual Innovation in the Workplace [J].Academy of Management Journal. 1994, 37(3): 580-607

[10]Zhou J, George J M. When job dissatisfaction leads to creativity: Encouraging the expression of voice [J]. Academy of Management Journal. 2001, 44(4): 682-696.

Author in brief:

Zhang Chao, postgraduate studying in Guangxi University of Science and Technology, mainly engaged in human resource management. E-mail: $908192601 @$ qq.com. 